\title{
Two cases of COVID-19 monitored by a wearable biosensor-a case report
}

\author{
Willem Gielen $^{1,2}$, Kevin Andrew Longoria ${ }^{2} \wedge$, Reinier Alexander van Mourik ${ }^{2} \wedge$ \\ ${ }^{1}$ Department of Internal Medicine, Randers Regional Hospital, Randers, Denmark; ${ }^{2}$ Biostrap, Duarte, CA, USA \\ Correspondence to: Willem Gielen, MD, MSc. Randers Regional Hospital, Skovlyvej 15, 8930 Randers NØ, Randers, Denmark. \\ Email: willem.gielen@rm.dk.
}

\begin{abstract}
Wearable devices have gained popularity in recent years for tracking metrics related to personal health and well-being such as vital signs, motion, and sleep. Wearable devices are considered to have a very high potential value for detecting, monitoring, and controlling the spread of infectious diseases such as COVID-19, based on their ability to collect data in a non-invasive and contactless manner. With the Biostrap wrist-worn device (Biostrap USA LLC, Duarte, CA, USA), a commercially available, clinically validated wearable device that uses photoplethysmography to automatically record physiological data such as resting heart rate, respiratory rate, oxygen saturation $\left(\mathrm{SpO}_{2}\right)$, and arterial stiffness (AS), we collected biometric data from 933 subjects. We present two cases of patients who have tested positive for the presence of severe acute respiratory syndrome (SARS-CoV-2), a 24-year-old man experiencing major symptoms and another a 49-year-old man with only intermittent fatigue, and show the marked changes in biometric measurements around dates of symptom onset and positive test. We observed a pattern of sustained respiratory rate elevation in both patients, punctuated by a sharp spike in heart rate and decreased AS. The latter contradicted our expectation that during the onset of symptoms of COVID-19, an increase in AS might occur.
\end{abstract}

Keywords: Case report; COVID-19; Biostrap; wearable

Received: 07 August 2020; Accepted: 24 January 2021; Published: 20 October 2021.

doi: $10.21037 /$ mhealth-20-134

View this article at: http://dx.doi.org/10.21037/mhealth-20-134

\section{Introduction}

In recent years, wearable devices have gained popularity for tracking metrics related to personal health and wellbeing, such as vital signs, movement, and sleep (1). Based on their ability to collect data in a non-invasive and contactless manner, wearable devices are considered to have a very high potential value for detecting, monitoring, and controlling the spread of infectious diseases such as COVID-19 (2).

We discuss two cases of patients who tested positive for the presence of severe acute respiratory syndromecoronavirus-2 (SARS-CoV-2) and the change in their biometrics as collected with the Biostrap wrist-worn device
(Biostrap USA LLC, Duarte, CA, USA), a commercially available, clinically validated wearable device (3) that automatically captures physiological data such as resting heart rate, respiratory rate, oxygen saturation $\left(\mathrm{SpO}_{2}\right)$, and arterial stiffness (AS) (4). AS is considered to be an emerging risk factor linked to the risk of myocardial infarction, dementia, and death (5) and refers to the arteries' ability to contract and dilate in response to pulses (6). Biostrap uses photoplethysmography (PPG) for arterial pulsation measurements related to the estimation of AS and cardiovascular aging assessment (4,7-9). Since COVID-19 affects endothelial cells (10), we were expecting AS to

\footnotetext{
^ ORCID: Willem Gielen, 0000-0002-0944-253X; Kevin Andrew Longoria, 0000-0001-6430-9304; Reinier Alexander van Mourik, 00000002-5941-6241.
} 


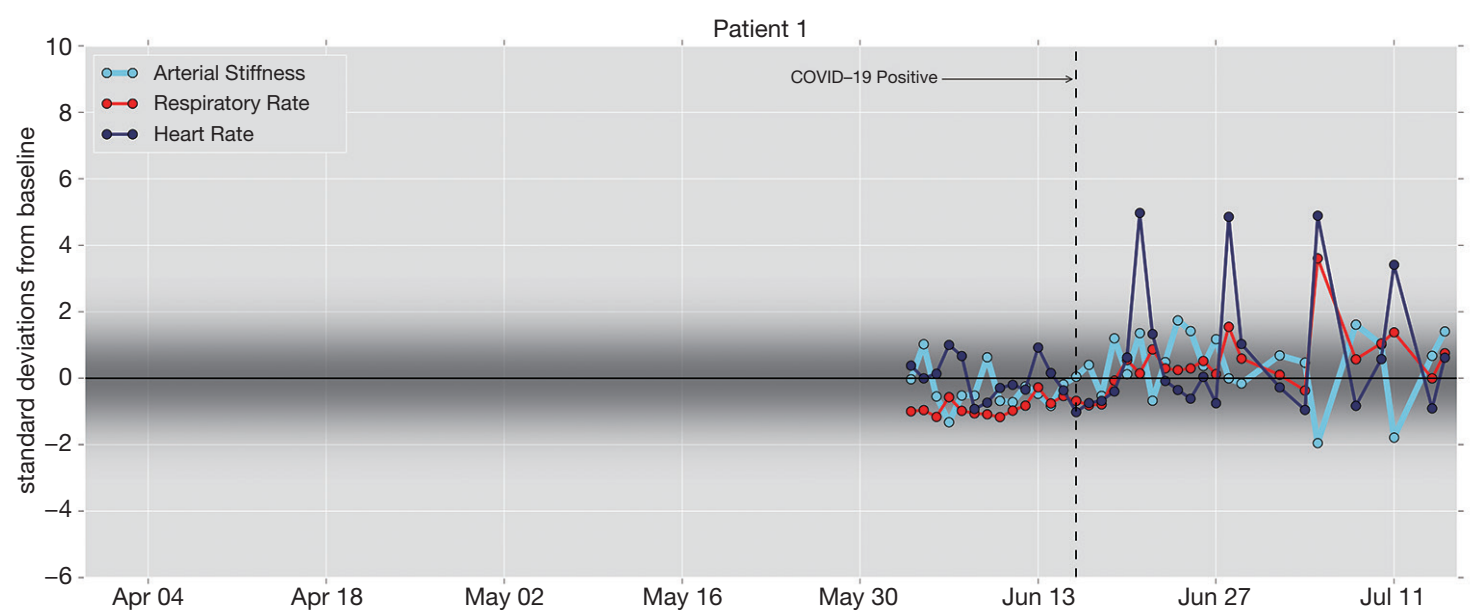

Figure 1 A 49-year-old man reported symptoms of intermittent fatigue. On June 16, a nasal swab test resulted in a positive diagnosis of SARS-CoV-2. Daily averages for each of four biometrics are shown as the deviation from baseline (i.e., normalized by median and standarddeviation-consistent median absolute deviation). The shading indicates where the deviations are expected for this person.

increase in the disease's presence. We present the following article in accordance with the CARE reporting checklist (available at http://dx.doi.org/10.21037/mhealth-20-134).

\section{Case presentation}

For 3.5 months during the COVID-19 pandemic, between April 12th and July 31, 2020, Biostrap users were given the opportunity to contribute de-identified biometric data for analysis to provide insight into the course of this disease. Additionally, a daily survey was administered through the Biostrap app to obtain information about symptoms, exposure, and COVID-19 diagnosis. A total of 933 participants were enrolled in this study, contributing over 2.5 million hours of biometric data and 43,000 surveys. All procedures performed in studies involving human participants were in accordance with the ethical standards of the institutional and/or national research committee(s) and with the Helsinki Declaration (as revised in 2013). Written informed consent was obtained from the patients.

\section{Patient 1}

A 49-year-old well-trained man reported no symptoms other than intermittent fatigue. On June 16, a nasal swab test resulted in a positive diagnosis of SARS-CoV-2.

\section{Patient 2}

A 24-year-old man experienced low-grade fever, dizziness, and nausea on June 26. Three days later, he reported a slight loss of taste, smell, and shortness of breath (decreased tolerance to exercise). An antibody test performed five days after symptom onset was negative, but a nasal swab test performed simultaneously resulted in a positive diagnosis of SARS-CoV-2. Symptoms progressively worsened with a complete loss of taste and smell and persistent shortness of breath. Two weeks after symptom onset, the patient could end quarantine, but he continues to experience limited exercise capacity one month after the initial onset.

\section{Biometric changes}

In both patients, we observed a pattern of sustained elevation in respiratory rate punctuated by a sharp spike in heart rate and decreased AS.

* With the first patient, as seen in Figure 1, the respiratory rate increased on June 20 and stayed elevated until June 29. The patient's heart rate spiked on June 22 and June 28. On July 5, the heart rate and respiration rate jumped while arterial and peripheral stiffness sharply declined (Note that the effect on the respiratory rate is muted in the plot 


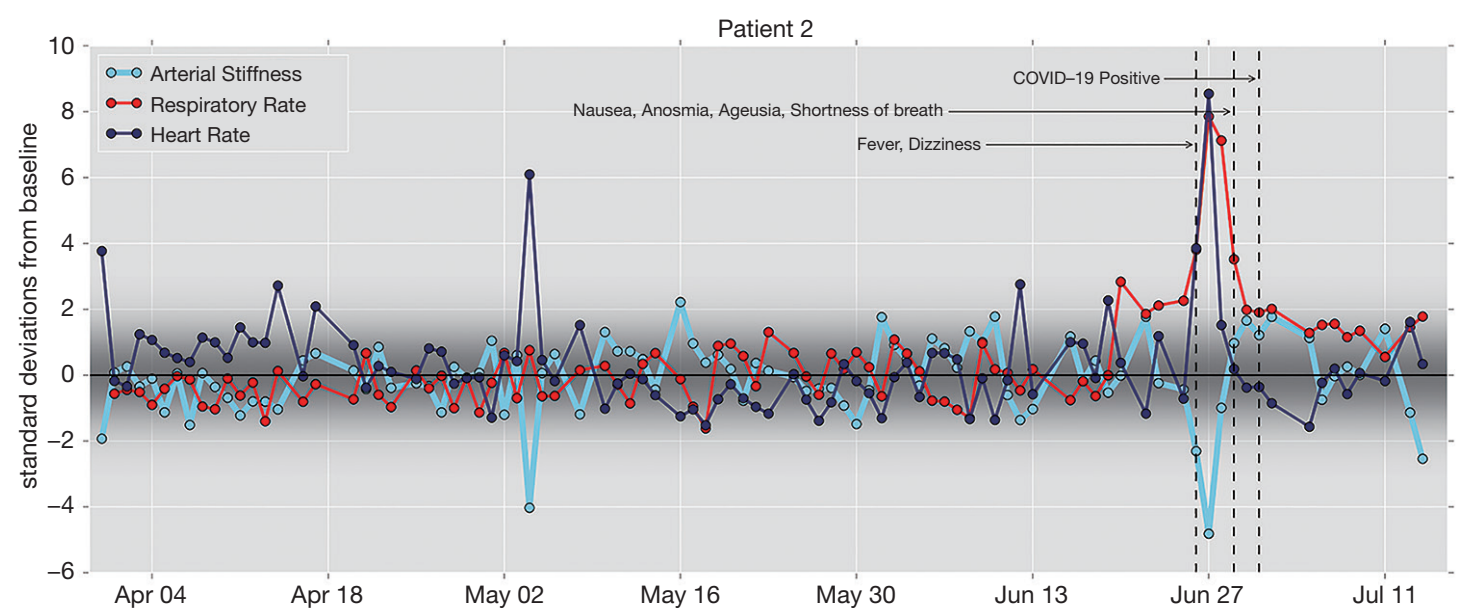

Figure 2 A 24-year-old man reported low-grade fever, dizziness, and nausea, later also loss of taste, smell, and shortness of breath. On July 1 a nasal swab test resulted in a positive diagnosis of SARS-CoV-2. Daily averages for each of four biometrics are shown as the deviation from baseline (i.e., normalized by median and standard-deviation-consistent median absolute deviation). The shading indicates where the deviations are expected for this person.

because of an insufficient baseline).

* The data of the second patient shows, according to Figure 2, that the respiratory rate increased on June 19 and stayed elevated until the end of the observation period. Heart rate and respiratory rate spiked, while AS sharply declined on and around June 27, consistent with the patient's onset of symptoms on June 26.

\section{Discussion}

While we observed changes in AS in both patients, the change contradicted our expectation that an increase of AS may occur during the onset of symptoms of COVID-19, increasing heart rate and respiratory rate. Instead, there appears to be decreased AS and increased physiological parameters, specifically resting heart rate and respiratory rate.

A possible explanation is that increased aortic systolic pressure results in higher wall stress, resulting in decreased AS. A further study must show us the actual value of, in particular, arterial stiffness as part of the early biometric detection of diseases like COVID-19.

\section{Acknowledgments}

Funding: None.

\section{Footnote}

Reporting Checklist: The authors have completed the CARE reporting checklist. Available at http://dx.doi.org/10.21037/ mhealth-20-134

Conflicts of Interest: All authors have completed the ICMJE uniform disclosure form (available at http://dx.doi. org/10.21037/mhealth-20-134). WG fulfills an unpaid position as Chief Medical Officer at Biostrap; KL fulfills a paid position as Chief Science Officer at Biostrap, outside the submitted work; RvM fulfills a paid position as Data Scientist at Biostrap, outside the submitted work.

Ethical Statement: The authors are accountable for all aspects of the work in ensuring that questions related to the accuracy or integrity of any part of the work are appropriately investigated and resolved. All procedures performed in studies involving human participants were in accordance with the ethical standards of the institutional and/or national research committee(s) and with the Helsinki Declaration (as revised in 2013). Written informed consent was obtained from the patients. A copy of the written consent is available for review by the editorial office of this journal.

Open Access Statement: This is an Open Access article 
distributed in accordance with the Creative Commons Attribution-NonCommercial-NoDerivs 4.0 International License (CC BY-NC-ND 4.0), which permits the noncommercial replication and distribution of the article with the strict proviso that no changes or edits are made and the original work is properly cited (including links to both the formal publication through the relevant DOI and the license). See: https://creativecommons.org/licenses/by-nc-nd/4.0/.

\section{References}

1. Swan M. The Quantified Self: Fundamental Disruption in Big Data Science and Biological Discovery. Big Data 2013;1:85-99.

2. Nilashi M, Asadi S, Abumalloh RA, et al. Intelligent Recommender Systems in the COVID-19 Outbreak: The Case of Wearable Healthcare Devices. Journal of Soft Computing and Decision Support Systems 2020 31;7:8-12.

3. Dur O, Rhoades C, Ng MS, Elsayed R, et al. Design Rationale and Performance Evaluation of the Wavelet Health Wristband: Benchtop Validation of a Wrist-Worn Physiological Signal Recorder. JMIR Mhealth Uhealth 2018;6:e11040.

doi: 10.21037/mhealth-20-134

Cite this article as: Gielen W, Longoria KA, van Mourik RA. Two cases of COVID-19 monitored by a wearable biosensor-a case report. mHealth 2021;7:62.
4. Takazawa K, Tanaka N, Fujita M, et al. Assessment of vasoactive agents and vascular aging by the second derivative of photoplethysmogram waveform. Hypertension 1998;32:365-70.

5. Zieman SJ, Melenovsky V, Kass DA. Mechanisms, pathophysiology, and therapy of arterial stiffness. Arterioscler Thromb Vasc Biol 2005;25:932-43.

6. O'Rourke MF, Kelly RP. The Arterial Pulse. J Intensive Care Med 1992. doi: 10.1177/088506669200700609.

7. Baek HJ, Kim JS, Kim YS, et al. Second derivative of photoplethysmography for estimating vascular aging. 2007 6th International Special Topic Conference on Information Technology Applications in Biomedicine. IEEE, 2007:70-2.

8. Pilt K, Ferenets R, Meigas K, et al. New photoplethysmographic signal analysis algorithm for arterial stiffness estimation. ScientificWorldJournal 2013;2013:169035.

9. Nichols WW. Clinical measurement of arterial stiffness obtained from noninvasive pressure waveforms. Am J Hypertens 2005;18:3S-10S.

10. Varga Z, Flammer AJ, Steiger P, et al. Endothelial cell infection and endotheliitis in COVID-19. Lancet 2020;395:1417-8. 